\title{
ON THE VOLUME MEASUREMENT OF WATER FILTERED BY A PLANKTON PUMP, WITH SOME OBSERVATIONS ON THE DISTRIBUTION OF PLANKTONIC ANIMALS
}

\author{
By H. Barnes \\ The Marine Station, Millport
}

INTRODUCTION

Winsor \& Walford (I936) have suggested that variations in replicate vertical plankton hauls can be explained on a random distribution of the population which is affected by variations in the volume of water filtered, and the results of Silliman (1946) and Barnes (I949) are in apparent agreement with this suggestion. It might be expected that the use of a pump would eliminate such volume errors. Further, in view of the increased attention now being paid to the use of pumping methods for obtaining plankton samples, it is desirable to know the accuracy, under various conditions, of the volume estimation in such samples. The use of the pump has been described by Gibbons \& Fraser (1937). Comparison of nets, pumps and the Clarke-Bumpus sampler has been given by Wiborg (I948).

\section{The ACcuracy of Filling a TANK}

Various methods have been used for estimating the volume of water pumped, the simplest technique consisting of filtering the water through a net into a calibrated tank to a series of marks. This method has been used in this laboratory. An ex-National Fire Service pump fitted with $2 \frac{1}{2}$ in. armoured hose has been used, the water being pumped into a galvanized iron tank of dimensions $60 \times 60 \times 100 \mathrm{~cm}$., i.e. a total capacity of approximately 4001 .

The volume of water pumped into this tank in any experiment was determined in the following way. After taking the sample a known volume of concentrated dye solution was added to the water and, after thoroughly mixing, a sample of the coloured liquid was taken and its transmittancy determined using the appropriate filters. The dilution was then obtained by reference to a calibration curve for dilution and transmittancy. The transmittances were determined by means of the Spekker Absorptiometer using $20 \mathrm{~cm}$. cells. It was necessary to construct a calibration curve each day using the water pumped on that occasion since the amount of suspended matter and organisms in the water, contributing to the absorption, varies from day to day. The accuracy of such volume determinations was approximately $\pm \mathrm{I} 1$.

The procedure was as follows. Having adjusted the pump throttle and valve (see p. 654) to deliver water at an approximately known rate, the person in 
charge of the delivery hose filled the tank to a mark and removed the hose. As the water level approached the mark the hose was raised so that it could be quickly moved clear of the tank when the desired level was reached. At the same time the water delivered at the pump by-pass was collected and measured in a measuring cylinder (see later for discussion). After filling up to a mark in this way, the concentrated dye solution was added to the water in the tank, and after stirring a subsample was taken. This was repeated several times, the tank being carefully washed out with the hose between each experiment. The transmittances of the samples were then determined and the volumes of water taken in the tank calculated. Results of the first series are given in Table I. (The results given in Tables I-III were obtained with the engine running continuously throughout each series.)

\section{Table i. First Pump Samples taken on Pier}

Nominal volume taken, 2001 ; weather rather cold, little wind; pumping speed approximately $2001 . / \mathrm{min}$.

$\begin{array}{lcc} & \text { Volume } & \text { Volume, by-pass } \\ & (1 .) & (\mathrm{ml} .) \\ & 204 & 3543 \\ & 206 & 35 \mathrm{IO} \\ & 205 & 35 \mathrm{I} 7 \\ & 192 & 3548 \\ & 200 & 359 \mathrm{I} \\ & \mathrm{I} 9 \mathrm{I} & 3638 \\ & \mathrm{I} 90 & 3600 \\ & 20 \mathrm{I} & 3622 \\ \text { Mean } & \mathrm{I} 90 & 364 \mathrm{I} \\ \text { Standard deviation } & \mathrm{I} 97 \cdot 7 & 3579 \\ \text { Coefficient of variation (\%) } & 6 \cdot 8 & 5 \mathrm{I} \\ & 3 \cdot 4 & \mathrm{I} \cdot 4\end{array}$

The factors influencing the accuracy with which the required volume is obtained, when attempting to fill a tank up to a mark in this way, are the judgement of the person manipulating the hose, particularly in relation to movement of water in the tank, and his efficiency in removing the hose after the mark has been reached. With practice one tends to allow for the small amount added during the removal of the hose. Any change in the speed of pumping will affect the accuracy by its effect on these two factors. It is evident from the results that under these working conditions the volume of water by this method can be taken with reasonable precision and that the variations are very much less than those encountered in plankton sampling.

In the second experiment the pumping speed was increased and the same number of samples taken.

The greater pumping speed increases the motion of the water in the tank and gives more foam on the surface, both factors tending to make the estimation of the point at which the mark has been reached more difficult. The error due to water being added whilst removing the hose is also increased. However, 
even with these possible sources of increased errors and under slightly more adverse weather conditions the accuracy of the volume measurement is unchanged. It should be noted that high pumping speeds are undesirable in collecting plankton since they may lead to the washing of material through the net, and to damage of the collected material.

\section{Table II. Second Pump Samples taken on Pier}

Nominal volume taken, 3301 ; weather, cold with some wind; pumping speed approximately $3501 . / \mathrm{min}$.

Mean

Volume
$(1$.
332
331
324
324
344
340
340
326
306
330
II.5
$3 \cdot 5$

Volume, by-pass
(ml.)
1569
I589
I573
I572
I579
I5677
I581
I559
I547
I571
I2.4
0.8

Coefficient of variation (\%)

The above experiments were repeated on board ship.

Here judgement in filling up to the mark is very considerably hampered by any movement, which if the tank is filled to the higher marks may even result in loss of water.

\section{Table III. Pump Samples Taken on Board Ship}

Nominal volume taken, 2001 .; weather, some wind, fairly cold; pumping speed approximately $150 \mathrm{l} . / \mathrm{min}$.

Mean

Standard deviation

Coefficient of variation $(\%)$

$\begin{array}{cc}\begin{array}{c}\text { Volume } \\ (1 .)\end{array} & \begin{array}{c}\text { Volume, by-pass } \\ (\mathrm{ml} .)\end{array} \\ 219 & 3375 \\ \text { I99 } & 3380 \\ \text { 195 } & 3295 \\ \text { I95 } & 3420 \\ \text { I97 } & 3380 \\ \text { I8I } & 3440 \\ \text { I86 } & 3350 \\ 200 & 3375 \\ 206 & 3425 \\ \text { I97.6 } & 3382 \\ \text { II.0 } & 43 \cdot 8 \\ 5.6 & \mathrm{I} \cdot 3\end{array}$

Although the error in the measurement of the volume is still quite small it is greater than at double the pumping speed on shore, and with increasing adversity of weather conditions the error of volume measurement on board might be expected to increase rapidly. It should also be noted that during the experiments described no net was used and no material was collected; attention could therefore be focused entirely on filling the tank. 


\section{Calibration of the By-Pass}

On ship, however, even under good weather conditions, the use of tanks can hardly be said to be a convenient technique of volume measurement, since for continuous work two rather cumbersome tanks taking up considerable deck space must be employed, one to be emptying whilst the other is in use. Consideration was given, therefore, to other possible methods of volume measurement. With a pump running at constant speed the timing of the delivery, once it was calibrated (and if checked at intervals) would be satisfactory when using a constant length of hose. However, even with constant hose length, this is not possible with the type of pump in use here, since the rate of delivery is determined both by the position of the main valve and by the engine speed, the latter being controlled by a throttle whose setting cannot be accurately reproduced from day to day.

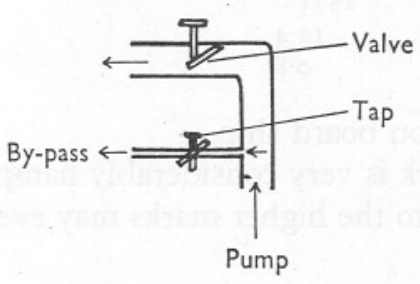

A

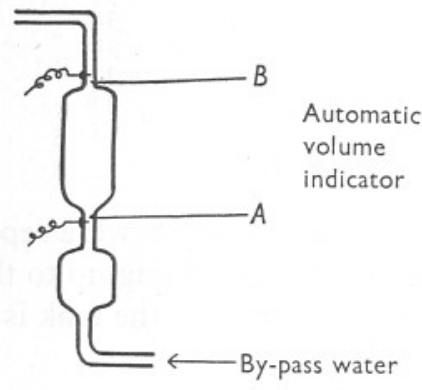

B

Fig. I.

It was therefore decided to determine whether the volume of water going through the by-pass (used to cool the engine) could be used as a measure of the volume pumped. This by-pass water is taken through a filter fitted with a cock which can be conveniently used to take a sample. The amount of water forced into the by-pass depends both upon the position of the main valve (which as it is closed causes considerable back pressure) as well as upon the engine speed. At a given engine speed the volume of by-pass water increases as the valve is closed and therefore as the volume pumped decreases. The arrangement is indicated in Fig. IA.

The results already given (Tables I-III) show that at a given engine speed and main valve position the amount of water delivered from the by-pass was constant for a constant volume collected (within the limits of error of the latter), and under these conditions the error in the volume of by-pass water is not greater than the error in filling the tank. The factors contributing to the errors of the two estimates of volume pumped are not identical; in taking the by-pass water co-ordination with the person working the hose is of importance for accurate work. That the coefficient of variation of the by-pass volume is 
less than that of the tank volume suggests that the co-ordination between the two workers was excellent and that much of the error in taking the tank volume is due to the water added when putting in and taking out the hose, since the by-pass water was taken when the person working the hose gave a shout at the beginning of the experiment and when the mark had been reached, and since manipulation of the vessel collecting the by-pass water was simpler than removal of the hose.

That a constant by-pass volume was obtained for other valve positions and engine speeds is shown by the results in Table IV. The actual volume delivered was not measured in these experiments, but the tank was filled up to a mark.

\section{Table IV. By-Pass Volumes From Pump Samples at Different Valve Positions}

Samples taken on pier; nominal volume taken, 330 1.; weather, cold with some wind; pumping speed approximately $330 \mathrm{l} . / \mathrm{min}$.

\begin{tabular}{|c|c|c|c|}
\hline Main valve postion... & 2 turns & $\begin{array}{c}3 \frac{1}{2} \text { turns } \\
\text { Volume (ml.) }\end{array}$ & 4 turns \\
\hline & $\begin{array}{l}\text { I36I } \\
\text { I273 } \\
\text { I304 } \\
\text { I356 } \\
\text { I354 } \\
\text { I352 } \\
\text { I264 } \\
\text { I273 }\end{array}$ & $\begin{array}{l}\text { I366 } \\
\text { I340 } \\
\text { I356 } \\
\text { I354 } \\
\text { I338 } \\
\text { I326 } \\
\text { I3II } \\
\text { I320 }\end{array}$ & $\begin{array}{l}\text { I465 } \\
\text { I475 } \\
\text { I528 } \\
\text { I453 } \\
\text { I396 } \\
\text { I394 } \\
\text { I360 } \\
\text { I406 }\end{array}$ \\
\hline Mean & I3I 7 & I339 & I435 \\
\hline $\begin{array}{l}\text { Standard deviation } \\
\text { Coefficient of variation }(\%)\end{array}$ & $\begin{array}{r}44.5 \\
3.4\end{array}$ & $\begin{array}{l}\text { I9 } \\
\text { I. } 4\end{array}$ & $\begin{array}{l}55 \\
3.8\end{array}$ \\
\hline
\end{tabular}

Note. These experiments were not done on the same day. The engine speeds would be different, which accounts for similar volumes being obtained with different values of cock position used.

Under given working conditions of fixed valve position and fixed running speed a satisfactory calibration could therefore be obtained between volume of water pumped and by-pass volume. The main valve position is readily reproduced and maintained but a given engine speed is difficult to reproduce. However, with fixed valve position it might be expected that for small changes in engine speed the by-pass water would be constant for a constant volume pumped, i.e. changes in engine speed would affect both volumes of water in the same proportion. Table $\mathrm{V}$ gives some results of experiments with varying engine speeds at two fixed valve positions.

For small changes in engine speed, at fixed positions of the valve, the delivery at the by-pass is a satisfactory measure of the volume pumped. A calibration of the pump is therefore possible in terms of the by-pass water. After calibration it would then only be necessary to measure the by-pass water in order to compute the volume of water pumped at a given valve position and engine speed. This by-pass water could be collected in a measuring cylinder. 
In order to ensure that the engine speed is approximately constant throughout any given series the preliminary adjustments have been made with the aid of a simple pressure-measuring device, utilizing the pressure developed in an upright tube at right angles to the direction of flow. As a pressure meter an ex-R.A.F. rate-of-climb indicator has been used. As supplied it records rate of change of pressure, but if the air escape is blocked then actual pressures are recorded in arbitrary units and the instrument is then far more sensitive than the similarly constructed altimeters or air speed indicators. This was attached to one of the two similar paired cocks on the by-pass filters (only one of these

\section{Table V. By-Pass Volumes at different Engine Speeds (at Two Valve Positions)}

Samples taken on pier; nominal volume taken, 3301 .; weather, good; pumping speed approximately $330 \mathrm{l} . / \mathrm{min}$.

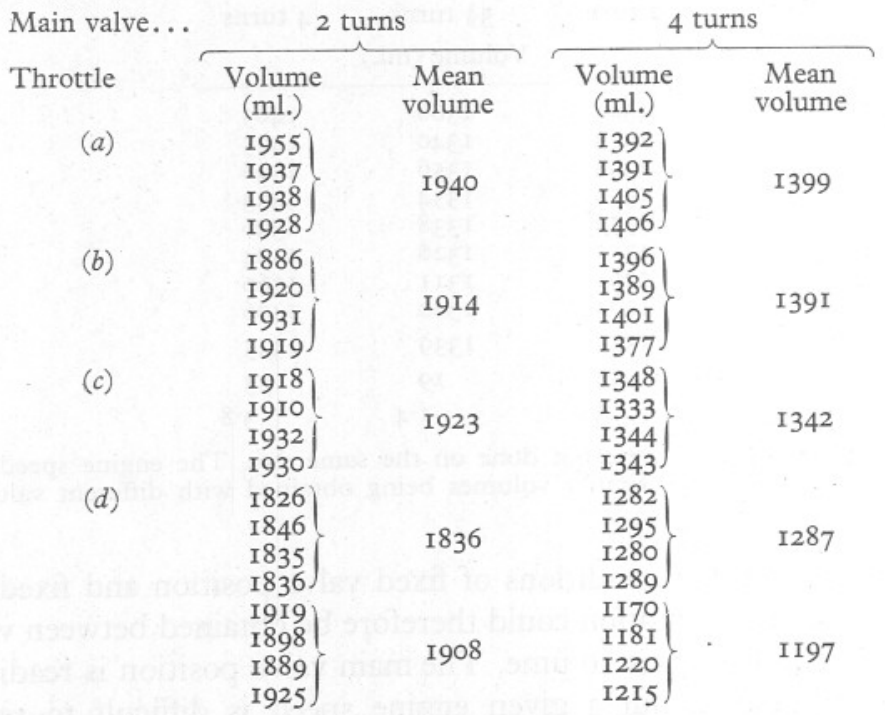

$(a),(b),(c)$ and $(d)$ represent very considerable successive increases of engine speed which are, however, different in the two separate experiments since the position of the main valve varied ( 2 turns and 4 turns).

cocks can be used at the same time; a simple valve allows transfer from one to the other), the second being used to collect the water. A fixed position is necessary and metal tubing and metal unions were used for connexions both to the cock and to the pressure meter.

It was shown that when the pressure was adjusted by means of the throttle to a given value as indicated by this meter a constant volume of water was pumped (at constant main valve position, which is readily reproduced). That this is so is indicated by the results given in Table VI. 
Collection of the by-pass water, followed by measurement of its volume in a cylinder, is not very convenient, although a good deal more so than the use of two large tanks, and a device has therefore been made which gives a signal when a known volume of water has been delivered. This consists of a vessel (Fig. IB) with a large and small section connected to the by-pass cock and having platinum electrical contacts at the entrance and exit of the main bulb. The small lower bulb serves to delay the first contact after the by-pass water has been turned on, thus giving the person working the hose time to get ready. The contacts are

\section{Table VI. By-Pass Volumes at Different Pressures}

Samples taken on pier; nominal volume taken, 330 1.; weather, good; constant main valve position; pressure changed by changing engine speed.

\begin{tabular}{|c|c|c|}
\hline $\begin{array}{c}\text { Pressure } \\
\text { (arbitrary units) }\end{array}$ & $\begin{array}{l}\text { Volume } \\
\text { (ml.) }\end{array}$ & $\begin{array}{l}\text { Mean volume } \\
\text { (ml.) }\end{array}$ \\
\hline \multirow[t]{2}{*}{$5 \cdot 2$} & 25261 & \multirow[b]{2}{*}{2537} \\
\hline & $\begin{array}{l}2527 \\
2558\end{array}$ & \\
\hline $6 \cdot 6$ & $\begin{array}{l}2760 \\
2775\end{array}$ & 2768 \\
\hline $7 \cdot 8$ & $\begin{array}{l}3586 \\
3543 \\
3626\end{array}$ & 3585 \\
\hline \multirow[t]{10}{*}{$5 \cdot 2^{\star}$} & $2480)$ & \multirow{3}{*}{2492} \\
\hline & $\left.\begin{array}{l}2512 \\
2483\end{array}\right\}$ & \\
\hline & 2495 & \\
\hline & $25 \mathrm{I} 4$ & \multirow{3}{*}{$25 \mathrm{II}$} \\
\hline & 2508 & \\
\hline & 25I2) & \\
\hline & 2504 & \multirow{4}{*}{2528} \\
\hline & $\begin{array}{l}245^{8} \\
2565\end{array}$ & \\
\hline & 2618 & \\
\hline & 2493 & \\
\hline
\end{tabular}

* Between these three series the cock was moved and readjusted and the pressure meter taken down and reassembled.

connected to a thermionic relay in circuit with a bell. Contact is made immediately the water reaches $A$ and the bell rings; the circuit is then broken by means of a switch, which puts the second contact in circuit, and the bell rings again when the water reaches the second contact at $B$. The person working the hose collects water between the ringing of the first and second bells.

Using this device the volume of water in the tank can be accurately and conveniently taken. The volume pumped for a fixed volume of the by-pass (i.e. volume of large bulb) with fixed valve position and approximately constant engine speed (adjusted by pressure meter) can be varied by inserting a tap at the inlet to the lower bulb. However, in view of the possibility of such a tap slipping and since in general only a small number of different units of volumes are likely to be required at one period in this type of work, a series 
of interchangeable tubes of varying bore have been used between the by-pass delivery (kept with cock fully open) and the entrance to the apparatus.

Using this method the results in Table VII were obtained. The apparatus was dismantled between the three runs which were done at intervals of several days, the volume being measured by the method already outlined. Once calibrated (which can be done on shore) the apparatus may be used to collect known volumes of water without the use of large tanks. A small vessel into which the collecting net can be held is used, the net being kept under the water during filtration.

\section{Table VII. Volumes in Tank for Fixed By-Pass Volume}

Nominal volume taken 2001 .; weather, good on shore, only moderate on ship; pumping speed approximately I $701 . / \mathrm{min}$.; separate days' experiments.

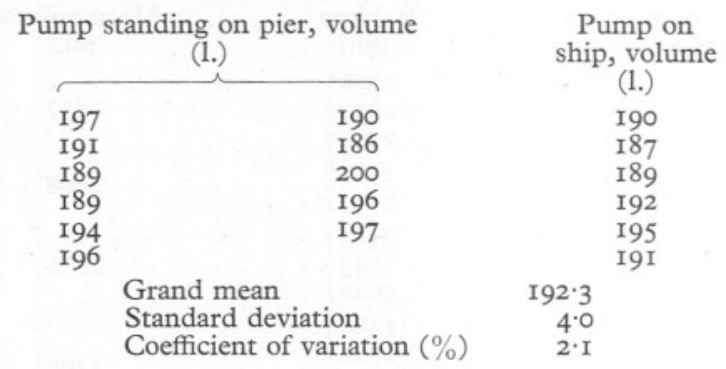

\section{The Results}

If the assumptions of Winsor \& Walford are correct, samples taken by a calibrated pump should show considerably less variation than net samples. So far only a small number of samples have been taken and analysed. In the first series of experiments approximately rooo 1 . were pumped for each sample and four consecutive samples were taken. The total time to take one sample was of the order of $6 \mathrm{~min}$. ( $170 \mathrm{l} . / \mathrm{min}$.), and allowing for the time taken in changing the nets and bottling off the catch the whole collection occupied about $\frac{3}{4} \mathrm{hr}$.

The net was a small fine net ( 200 meshes to the inch) held in a tank of water with the whole of the filtering surface immersed whilst the water being pumped was, as far as possible, not directed on to the net surface.

Four samples were taken, and since the collections took a considerable time they have been grouped in two pairs and the results of the analysis of variance

Table VIII. Composition of Plankton Samples from Four Consecutive Pump Hauls

\begin{tabular}{lrrrr}
\multicolumn{4}{c}{ Group } & \multicolumn{4}{c}{ Haul } \\
\cline { 2 - 5 } \multicolumn{1}{c}{ I } & 2 & 3 & 4 \\
Nauplii & 2662 & 2142 & 2200 & 2166 \\
Copepodites & 485 & 466 & 565 & 833 \\
Lamellibranchs & 608 & 882 & III8 & I279
\end{tabular}


are given below. In each sample three groups of organisms were counted, namely, copepods (adult stages), copepods (nauplius stages) and lamellibranch larvae (Table VIII).

Analysis of the variance ${ }^{1}$ of these data gives the following results:

$\begin{array}{lccc}\text { Main effects: } & \begin{array}{c}\text { Degrees of } \\ \text { freedom }\end{array} & \begin{array}{c}\text { Sum of } \\ \text { squares }\end{array} & \begin{array}{c}\text { Mean } \\ \text { squares }\end{array} \\ \text { Groups } & 2 & 0.744 \mathrm{I} & 0.372 \mathrm{I} \\ \text { Hauls } & \text { I } & 0.0062 & 0.0062 \\ \quad \text { Times } & \text { I } & 0.0370 & 0.0370 \\ \text { First-order interaction: } & & & \\ \quad \text { Groups-hauls } & 2 & 0.0142 & 0.007 \mathrm{I} \\ \quad \text { Groups-times } & 2 & 0.035 \mathrm{I} & 0.0176 \\ \quad \text { Hauls-times } & \text { I } & 0.0025 & 0.0025 \\ \text { Second-order interaction: } & & & 0.0055 \\ \quad \text { Groups-times-hauls } & 2 & 0.0109 & \\ \text { Totals } & \text { II } & 0.8500 & \end{array}$

The values for the times, group-haul, group-time and haul-time interaction are not significant. There is, therefore, no significant change in population, and the analysis can be simplified and regrouped as follows (this is equivalent to treating the data as four consecutive hauls):

$\begin{array}{lcll}\text { Groups }(\mathrm{G}) & \begin{array}{c}\text { Degrees of } \\ \text { freedom }\end{array} & \begin{array}{l}\text { Sum of } \\ \text { squares }\end{array} & \begin{array}{l}\text { Mean } \\ \text { square }\end{array} \\ \text { Hauls }(\mathrm{H}) & 2 & 0.744 \mathrm{I} & 0.3721 \\ \text { Residual } & 3 & 0.0457 & 0.0152 \\ 0.0100\end{array}$

The mean square for the hauls is not significant. $\sigma_{\mathrm{GH}}^{2}$ is a measure of the within-haul variance

$$
\sigma_{\mathrm{GH}}^{2}=0.0100 \text {. }
$$

Standard deviation $=\sigma_{\mathrm{GH}}=0 \cdot 1000=\log \mathrm{I} \cdot 259$, corresponding to a coefficient of variation of $25.9 \%$.

A further pair of hauls gave $21 \%$ as the coefficient of variation of a single observation, the conditions being similar to those of the first series.

These results indicate that little improvement has been effected by the use of the pump, and a third pair substantiated these results. It was thought that the manipulation of the catch on board was a possible source of error, and in a fourth series a pair of nets was used for the filtration. Two samples were taken of 220 l., the total time between beginning the first haul and completing the second being less than Io min. These nets were new and 'identical' and were soaked for some time before use. After filtering the pumped water, the nets were carefully transferred to buckets without removing the collecting bucket and taken to the laboratory where the catch was removed with extreme

\footnotetext{
${ }^{1}$ Logs of catches have been used. The hauls have been separated into Haul I and Haul 2 since there is some evidence that the first haul of a series is different from the second, due to the state of the net. The above results do not substantiate this suggestion.
} 
care using a fine jet to wash down the catch. A large number of species were counted and thanks are due to Dr S. M. Marshall for counting this set. The analysis of the variance of the data yields the following:

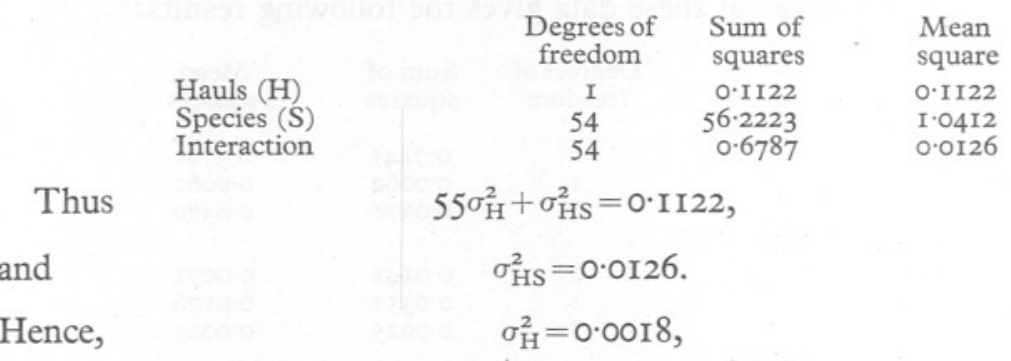

corresponding to a standard deviation of $0 \cdot 0424=\log \mathrm{I} \cdot \mathrm{IO}$, giving a coefficient of variation of $10.3 \%$.

Further,

$$
\sigma_{\mathrm{HS}}^{2}=0.0126,
$$

or a standard deviation of $0 \cdot \operatorname{II} 23=\log \mathrm{I} \cdot 295$, corresponding to a coefficient of variation of $29.5 \%$.

The standard deviation of a single observation is

$$
\sqrt{ }\left(\sigma_{\mathrm{H}}^{2}+\sigma_{\mathrm{HS}}^{2}\right)=\sqrt{ } 0 \cdot 0 \mathrm{I} 44=0 \cdot \mathrm{I} 2=\log \mathrm{I} \cdot 3 \mathrm{I} 8,
$$

corresponding to a coefficient of variation of $3 \mathrm{I} \cdot 8 \%$.

Table IX. The Distribution of $\chi^{2}$ Derived from Poisson Series

(as expected on a Random Distribution), and Net and Pump

\begin{tabular}{|c|c|c|c|}
\hline$\chi^{2}$ value & Poisson & Nets & Pump \\
\hline $0-0.0039$ & 5 & $4 \cdot 5$ & 5.5 \\
\hline-0.0158 & 5 & I. 5 & \\
\hline-0.0642 & 10 & $3 \cdot 7$ & 3.6 \\
\hline-0.148 & IO & $5 \cdot 2$ & 9.1 \\
\hline-0.455 & 20 & 10.4 & $9 \cdot 1$ \\
\hline$-\mathrm{I} \cdot 074$ & 20 & II $\cdot 2$ & $5:$ \\
\hline$-I \cdot 642$ & IO & $9 \cdot 0$ & $\mathrm{I} 2 \cdot 7$ \\
\hline$-2 \cdot 706$ & IO & II.9 & $7:$ \\
\hline$-3.84 \mathrm{I}$ & 5 & II $\cdot 2$ & 3. \\
\hline$>3.84 \mathrm{I}$ & 5 & $3 I \cdot 3$ & $40^{\circ}$ \\
\hline
\end{tabular}
SAMPLES FOR ALL ORGANISMS

\section{Discussion}

The results from this small series of pump samples do not show any less variability than found with the net samples, and their similarity is confirmed on comparing the values of $\chi^{2}$ for the two series. In the distribution of $\chi^{2}$, and in the relation between $\chi^{2}$ and sample size, the two series show similar trends as shown in Tables IX and X, in particular the fact that even with pump samples the large values of 'sample size', i.e. population density high, contribute a very large proportion of the abnormally high discrepancies. Doubt is 
therefore cast upon the assumption that the variability of net hauls is due to variation in the volumes of water filtered, since this was controlled in the pump samples, and it seems desirable to re-examine the assumption that the animals are randomly distributed, since it was upon a random population that variable volume filtered was supposed to act. Work designed to investigate the distribution of the organisms, using a new method of sampling, is already in progress.

\section{Table X. Sum of $\chi^{2}$ by Sample Size (Population Density)}

Numbers in brackets indicate number of samples in each group.

$\begin{array}{ccc} & \text { Net } & \text { Pump } \\ 5-40 & \text { I28.928 (50) } & 8.598 \text { (I2) } \\ 40-170 & \text { I00.513 (44) } & 65.401 \text { (I9) } \\ 170-400 & 69 \cdot 076 \text { (I9) } & 5 \mathrm{I} \cdot 699 \text { (7) } \\ 400-1000 & \text { I6I.507 (9) } & \text { I28.690 (II) } \\ >\text { I000 } & \text { I726. I5I (I2) } & 227.7 \text { I } 8 \text { (6) }\end{array}$

I wish to thank Dr R. Robb for his criticisms and to acknowledge the help of Mr R. Kerr and Mr C. Davidson in the experimental work.

\section{SUMMARY}

The accuracy of volume estimation in filling a marked tank by means of a plankton pump has been determined. The method even in its simplest form is satisfactory under good conditions. Further refinements, in which the plankton was filtered off, after filling a modified tank (for example with an overflow device) would no doubt increase the accuracy.

A device is described by which, using an ex-N.F.S. pump, a constant (but variable by selection) volume of water can be taken without the use of large tanks.

A small number of sets of samples taken with adequate volume control indicate the same order of variability as net hauls. Comparison of the distribution of $\chi^{2}$ for paired samples with nets and pumps also indicates variation of a similar type.

These results suggest that the variability of net hauls is not entirely due to the variations in the volume of water filtered. Further work is in hand to elucidate this question. 


\section{REFERENCES}

BARNES, H., 1949. A statistical study of the variation in vertical plankton hauls with special reference to the loss of the catch with divided hauls. Fourn. Mar. Biol. Assoc., Vol. 28, pp. 429-46.

GibBons, S. G. \& Fraser, J. H., 1937. The centrifugal pump and suction hose as a method of collecting plankton samples. Fourn. Cons. Int. Explor. Mer, Vol. I2, pp. $155-70$.

Silliman, R. P., 1946. A study of variability in plankton townet catches of Pacific pilchard Sardinops caerulea eggs. Fourn. Mar. Res., Vol. 6, pp. 74-83.

WIBORG, K. F., I948. Experiments with the Clarke-Bumpus plankton sampler and with a plankton pump in the Lofoten area in Northern Norway. Rep. Norwegian Fish. Mar. Investig., Vol. 9, No. 2.

WINSOR, C. P. \& WALFORD, L. A., I936. Sampling variations in the use of plankton nets. Fourn. Cons. Int. Explor. Mer, Vol. I I, pp. I90-204. 